\title{
Effect of 12 Heat Treatment Conditions After HIP Process on Microstructural Refurbishment in Cast Nickel-Based Superalloy, GTD-111
}

\author{
P. Wangyao ${ }^{1, *}$, V. Krongtong ${ }^{2}$, N. Panich', N. Chuankrerkkul ' and G. Lothongkum ${ }^{3}$ \\ 'Metallurgy and Materials Science Research Institute (MMRI), \\ Chulalongkorn University, Bangkok, Thailand \\ ${ }^{2}$ National Metals and Materials Technology Center (MTEC), Pathumthani, Thailand \\ ${ }^{3}$ Metallurgical Engineering Dept., Faculty of Engineering, Chulalongkorn University, \\ Bangkok, Thailand
}

(Received October 25, 2006: final form November 3,2006)

\begin{abstract}
The present work is an attempt to obtain the most suitable and practicable repair condition, which could provide the desired microstructural characteristics by rejuvenation method of hot isostatic pressing (HIP), followed by 12 heat treatment conditions for long-term serviced gas turbine blades, cast nickel based superalloy grade GTD-111 operated by Electricity Generating Authority of Thailand (EGAT). The hot isostatic pressing could mostly heal any internal structural voids and cracks (by means of sintering), which were generated during service. It was found that no microcrack was observed after a long time of HIP process such as for $18 \mathrm{ks}$ HIP time. However, microvoids were still found even after $18 \mathrm{ks}-\mathrm{HIP}$ process at $1473 \mathrm{~K}$ but in a very small amount. Furthermore, during solution treatment, coarse carbides and over-exposed coarse gamma prime precipitates, which had formed previously during service, would dissolve into the matrix. Then specimens were processed through a series of precipitation aging, which re-precipitated the strengthening phase to form the proper morphology in size and shape as well as distribution that is almost similar to the new one.
\end{abstract}

Metallography examination were performed by using scanning electron microscope and image analyzer after hot isostatic pressing and heat treatments to evaluate the rejuvenated microstructures.

Keywords: Hot Isostatic Pressing (HIP), Rejuvenation, Microstructural Repair, and Nickel-Based Superalloy GTD-111

\section{INTRODUCTION}

Nickel-based superalloys have been developed to be utilized at high temperature applications. The microstructures and mechanical properties (at low to high temperatures) can be related to their manufacturing processes. One of these processes is heat treatment, in which solutioning in most cases is followed by a single or a double aging sequence to precipitate homogeneous distributions of either cuboidal or spherical gamma prime within the grains interior as well as discrete grain boundary carbides $/ 1 /$. Full solution treatment or partial solution treatment temperatures including aging treatment(s) have been continually developed and modified to optimize the completed precipitation of

\footnotetext{
* Corresponding author: P. Wangyao.
}

Tel.: +662-218-4233; E-mail: panyawat@hotmail.com 
gamma prime phase in matrix of each long-term serviced superalloy. The size, volume fraction and distribution of gamma prime phase are very vital to control the creep strength at intermediate to high stresses. The proper heat treated microstructure can provide their phase stability, and adequately high strength and good ductility even after long-term thermal exposure.

Many mechanical properties are strongly related to the microstructures. In the new, heat treated alloy, the gamma prime $\left(\gamma^{\prime}\right)$ particles are arranged properly in a structure, which results in an optimum balance of tensile, fatigue, and creep properties $/ 1 \%$. Several previous research works /2-4/ had been carried out to investigate these relationships of microstructuremechanical properties. However, the superalloy microstructures could continually degrade with time at the elevated temperatures. Therefore, the use of these expensive materials requires a repair process providing the re-establishment of the initial properties and the original microstructure of the long-term used or damaged parts for the economic reason. The heat treatment processes for nickel-based superalloys continue to change in order to optimize numerous mechanical and physical properties $75,6 /$. This allows making the selection of heat treatment parameters becoming more advantage.

Usually, the alloy's standard heat treatment does not always work properly when applied to the long-term serviced microstructure to re-establish mechanical properties as well as to the welded superalloy components or to HIPed superalloy parts. For example, practical heat treatment cycles used for the most common industrial turbine rotating blade material, a cast polycrystalline GTD-111 is the following step: 1) Solution treatment at $1393 \mathrm{~K}$ for 7.2-14.4 ks followed by a rapid gas quench ( $25 \mathrm{~K}$ to $55 \mathrm{~K} / 60 \mathrm{~s}$ ) to below 923 $\mathrm{K}$ and 2) Precipitation aging at $1118 \mathrm{~K}$ for $86.4 \mathrm{ks}$ followed by a rapid gas quench to room temperature. The reason why the standard heat treatment does not often work well is that the $\gamma$ ' solution temperature for the alloy ranges from $1448 \mathrm{~K}$ to $1463 \mathrm{~K} / 1 /$. Therefore, the alloy was recommended to be solutioning treated at $1473 \mathrm{~K}$ to fully restore the microstructure after longterm service. However, if hot isostatic pressing (HIP) is applied before the re-heat treatments then the new condition to deal with the high temperature cycle will be needed to properly restore the serviced microstructure.

The cast nickel-based superalloy GTD-111 is used as a blade material in the first row high-pressure stage of gas turbines. The efficiency using at high temperatures of the alloy is superior by about $20 \mathrm{~K}$ in creep rupture strength in comparison with another cast nickel-based superalloy, IN-738LC. The hot oxidation and corrosion resistance of GTD-111 is much higher than that of IN-738LC. The alloy contains refractory elements such as $\mathrm{Mo}, \mathrm{W}, \mathrm{Ta}, \mathrm{Cr}$ and $\mathrm{Co}$ to prevent local hot corrosion $17 /$. The alloy has a multi-phase microstructure consisting of FCC $\gamma$ matrix, bimodal $\gamma^{\prime}$ precipitates (coarse and fine), $\gamma-\gamma^{\prime}$ eutectic, carbides and small amount of deleterious phases such as $\sigma, \delta, \eta$ and Laves phases $/ 8 /$.

According to previous work $19 /$, the rejuvenation process provides blades to double and in some cases, triple the lifetime as compared to the original ones. For alloy grades such as IN 738, IN 792, U 500, X-750 and the newer alloys such as GTD 111, GTD 11IDS, R80DS, and IN 939, which are used in many land base gas turbines, they have been rejuvenated and successfully reused in service. In each case, the creep life of blades expired when received for processing and then gave reliable service after rejuvenation.

However, up to the present, there are only a few research works $/ 10,11 /$, which have been studied about effect of heat treatment or HIP processes on microstructural refurbishment of the alloy. Therefore, the aim of this research work is to determine the most suitable and practicable repair-condition, which could provide the proper microstructural characteristics by rejuvenation method of hot isostatic pressing (HIP) followed by various heat treatments for long term exposed gas turbine blades, casting nickel-based superalloy grade GTD-111 after 20,000-hour service operated by Electricity Generating Authority of Thailand (EGAT).

\section{EXPERIMENTAL PROCEDURE}

The cast nickel-based superalloy in this study was GTD-111, with the following composition (mass \%): $13.5 \% \mathrm{Cr}, \quad 9.5 \% \mathrm{Co}, \quad 4.75 \% \mathrm{Ti}, \quad 3.3 \% \mathrm{Al}, \quad 3.8 \% \mathrm{~W}$, 
$1.53 \% \mathrm{Mo}, 2.7 \% \mathrm{Ta}, 0.09 \% \mathrm{C}$, and balance nickel. Rectangular plates, having a dimension of $1 \times 1 \times 10^{-4}$ $\mathrm{m}^{2}$, were cut from the most severe degradation zone of turbine blades. HIP condition is as follows: specimens were HIPed at pressure of $100 \mathrm{MPa}$ for $86.4 \mathrm{ks}$ at 1473 $\mathrm{K}$, and then the HIPed specimens were heat treated according to heat treatment conditions including solution treatment, primary and secondary precipitate aging treatments in vacuum furnace, see experimental heat treatment details in Table 1. Heat treated plates were cross sectioned in order to observe microstructure comparing to those of parallel grinded and polished surface of turbine blades. All sectioned samples were polished using standard metallographic techniques and were subsequently etched in marble etchant, which has chemical composition as the following: $10 \mathrm{~g} \mathrm{CuSO}_{4}, 50$ $\mathrm{ml} \mathrm{HCl}$, and $50 \mathrm{ml} \mathrm{H}_{2} \mathrm{O}$. The microstructures of heat treatment samples were studied by scanning electron microscope with secondary electron mode and image analyzer.

Table 1

Heat treatment conditions applied to long term exposed GTD-111

\begin{tabular}{|c|c|c|c|}
\hline No. & $\begin{array}{l}\text { Solution } \\
\text { annealing }\end{array}$ & $\begin{array}{c}\text { Primary } \\
\text { precipitate } \\
\text { aging }\end{array}$ & $\begin{array}{c}\text { Secondary } \\
\text { precipitate } \\
\text { aging } \\
\end{array}$ \\
\hline 1 & ---------------- & - & $\begin{array}{c}1118 \mathrm{~K} / 86.4 \\
\mathrm{ks}(\mathrm{AC})\end{array}$ \\
\hline 2 & ----- & $\begin{array}{c}1198 \mathrm{~K} / 3.6 \\
\mathrm{ks}(\mathrm{AC})\end{array}$ & $\begin{array}{c}1118 \mathrm{~K} / 86.4 \\
\mathrm{ks}(\mathrm{AC})\end{array}$ \\
\hline 3 & ---- & $\begin{array}{c}1328 \mathrm{~K} / 3.6 \\
\mathrm{ks}(\mathrm{AC})\end{array}$ & $\begin{array}{c}1118 \mathrm{~K} / 86.4 \\
\mathrm{ks}(\mathrm{AC})\end{array}$ \\
\hline $4^{*}$ & $\begin{array}{c}1398 \mathrm{~K} / 7.2 \\
\mathrm{ks}(\mathrm{AC})\end{array}$ & - & $\begin{array}{c}1118 \mathrm{~K} / 86.4 \\
\mathrm{ks}(\mathrm{AC})\end{array}$ \\
\hline 5 & $\begin{array}{c}1398 \mathrm{~K} / 7.2 \\
\mathrm{ks}(\mathrm{AC})\end{array}$ & $\begin{array}{c}1198 \mathrm{~K} / 3.6 \\
\mathrm{ks}(\mathrm{AC}) \\
\end{array}$ & $\begin{array}{c}1118 \mathrm{~K} / 86.4 \\
\mathrm{ks}(\mathrm{AC})\end{array}$ \\
\hline 6 & $\begin{array}{c}1398 \mathrm{~K} / 7.2 \\
\mathrm{ks}(\mathrm{AC})\end{array}$ & $\begin{array}{c}1328 \mathrm{~K} / 3.6 \\
\mathrm{ks}(\mathrm{AC})\end{array}$ & $\begin{array}{c}1118 \mathrm{~K} / 86.4 \\
\mathrm{ks}(\mathrm{AC})\end{array}$ \\
\hline 7 & $\begin{array}{c}1448 \mathrm{~K} / 7.2 \\
\mathrm{ks}(\mathrm{AC})\end{array}$ & - & $\begin{array}{c}1118 \mathrm{~K} / 86.4 \\
\mathrm{ks}(\mathrm{AC})\end{array}$ \\
\hline 8 & $\begin{array}{c}1448 \mathrm{~K} / 7.2 \\
\mathrm{ks}(\mathrm{AC}) \\
\end{array}$ & $\begin{array}{c}1198 \mathrm{~K} / 3.6 \\
\mathrm{ks}(\mathrm{AC})\end{array}$ & $\begin{array}{c}1118 \mathrm{~K} / 86.4 \\
\mathrm{ks}(\mathrm{AC})\end{array}$ \\
\hline 9 & $\begin{array}{c}1448 \mathrm{~K} / 7.2 \\
\mathrm{ks}(\mathrm{AC})\end{array}$ & $\begin{array}{c}1328 \mathrm{~K} / 3.6 \\
\mathrm{ks}(\mathrm{AC})\end{array}$ & $\begin{array}{c}1118 \mathrm{~K} / 86.4 \\
\mathrm{ks}(\mathrm{AC})\end{array}$ \\
\hline
\end{tabular}

\begin{tabular}{|c|c|c|c|}
\hline 10 & $\begin{array}{c}1478 \mathrm{~K} / 7.2 \\
\mathrm{ks}(\mathrm{AC})\end{array}$ & $-3 .--$ & $\begin{array}{c}1118 \mathrm{~K} / 86.4 \\
\mathrm{ks}(\mathrm{AC})\end{array}$ \\
\hline 11 & $\begin{array}{c}1478 \mathrm{~K} / 7.2 \\
\mathrm{ks}(\mathrm{AC})\end{array}$ & $\begin{array}{c}1198 \mathrm{~K} / 3.6 \\
\mathrm{ks}(\mathrm{AC})\end{array}$ & $\begin{array}{c}1118 \mathrm{~K} / 86.4 \\
\mathrm{ks}(\mathrm{AC})\end{array}$ \\
\hline 12 & $\begin{array}{c}1478 \mathrm{~K} / 7.2 \\
\mathrm{ks}(\mathrm{AC})\end{array}$ & $\begin{array}{c}1328 \mathrm{~K} / 3.6 \\
\mathrm{ks}(\mathrm{AC})\end{array}$ & $\begin{array}{c}1118 \mathrm{~K} / 86.4 \\
\mathrm{ks}(\mathrm{AC})\end{array}$ \\
\hline
\end{tabular}

* Standard Heat-Treatment condition

\section{RESULTS AND DISCUSSION}

\subsection{The microstructure of as-received alloy}

An optical micrograph, obtained from the transverse sections at about mid blade height of the airfoil, is shown in Fig. 1. The microstructure of as-cast alloy generally consists of extensive precipitation of ordered $\mathrm{Ll}_{2} \gamma^{\prime}$ intermetallic phase within dendrite core and in the interdendritic region. Carbides / carbonitrides, predominantly $\mathrm{MC}$ type, borides, sulphur-carbide and $\gamma-\gamma^{\prime}$ eutectic, which form during ingot solidification were found in smaller volume fraction locating along the interdendritic region, according to works $17,8 \%$. The chromium carbide $\left(\mathrm{M}_{23} \mathrm{C}_{6}\right)$ and agglomerated gamma prime particles can also be seen. Coalescence of the gamma prime particles, as a result of long-term service, seems to occur continually, causing larger and more rounded particles. This is most probably due to the slow cooling rates. The degree of degradation, as measured by the gamma prime particle size, usually increases with exposed time at service temperature. In this study, the

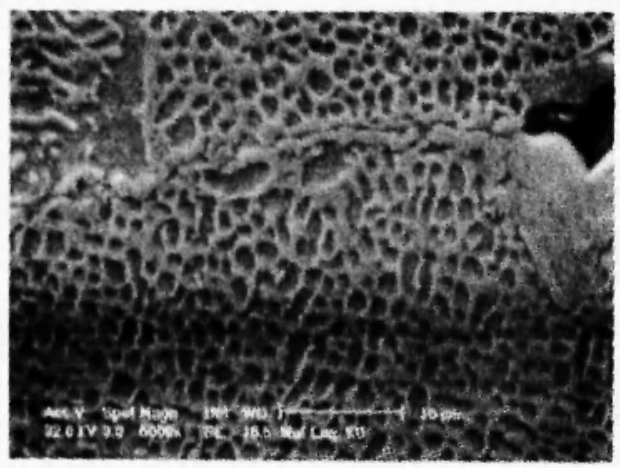

Fig. 1: As-received microstructure after long-term service showing the coalescence of $\gamma^{\prime}$ particles, areas of $\gamma-\gamma^{\prime}$ eutectic and grain boundary carbides 
coarse gamma prime particle size was approximately $1.2 \mu \mathrm{m}$. The airfoil microstructure shows significant degradation in service. The gamma prime particles had spheroidized and coarsened in the airfoil samples. This type of microstructure is theoretically expected to provide lower creep resistance during loading at high temperatures. Therefore, it is needed to recover microstructure to be the same as or similar to the original one by HIP and re-heat treatment processes.

\subsection{The microstructure of materials by HIP process}

The temperature of HIP process was selected so that the alloy yielded or crept in compression under the action of the applied hot pressure. The result is a significant reduction of internal voids (porosity) and/or microcracks with nearly full densification of the alloy. HIP is able to almost remove internal voids and promote diffusion bonding across the surfaces of the void, which is replaced by continuous material. Higher temperature and longer HIP time show the smaller internal void diameter $/ 5 \%$. It was found that the size and amount of remain microvoids decreased drastically when HIP was applied. Therefore, by SEM investigation in specimens, it was found that the microvoids were very rarely to be detected. This fact is very important to consider the advantage of HIP process for refurbishment of superalloy components. Figure 2 shows the etched microstructure of HIPed specimen with the uniform dispersion of some smaller coarse gamma prime

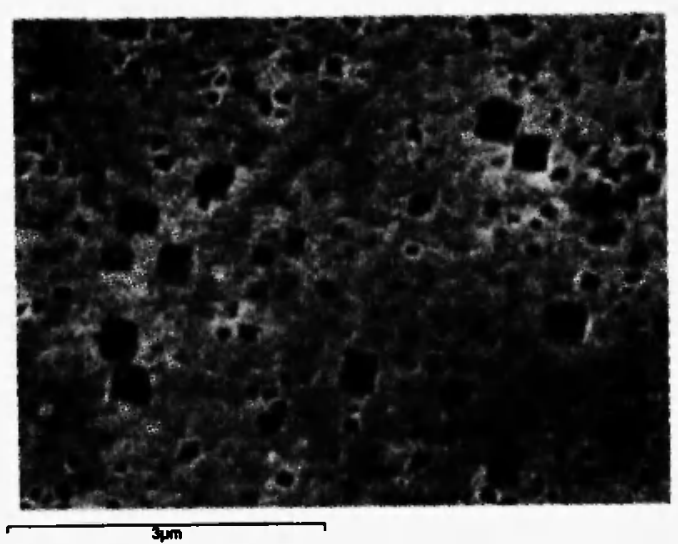

Fig. 2: HIPed microstructure showing partial dissolved gamma prime particles particles, which were partially dissolved into the matrix during HIP at high temperature. It should be noted that the previously existed coarse gamma prime particles could not be completely solutioned at $1473 \mathrm{~K}$ for $18 \mathrm{ks}$.

\subsection{The heat treated microstructure after HIP process}

All of the re-heat treatments after HIP process in long-term serviced turbine blade GTD-111 provided the various microstructural restoration characteristics with more homogeneous structure comparing to the longterm serviced one, as shown in the following. It was found that the heat treated microstructure according to program No. 1, which followed by only secondary aging, consists of the uniform distribution of fine gamma prime particles precipitating in the matrix as nearly cubic shape (see Fig. 3). It should be noted that the microstructure contains only a single size of precipitated gamma prime particles, which have the size in the narrow range $0.15-0.35 \mu \mathrm{m}$. In this structure, it could be counted that the heating during HIP process practically worked as solutioning at $1473 \mathrm{~K}$ for $18 \mathrm{ks}$ and then followed by aging at $1118 \mathrm{~K}$ for $86.4 \mathrm{ks}$. The microstructure after HIP process was already prepared for the next step, precipitation aging, in which previously existed coarse gamma prime particles were almost dissolved into the matrix. When precipitation (secondary) aging was applied, fine gamma prime particles re-precipitated in the matrix at a high volume fraction.

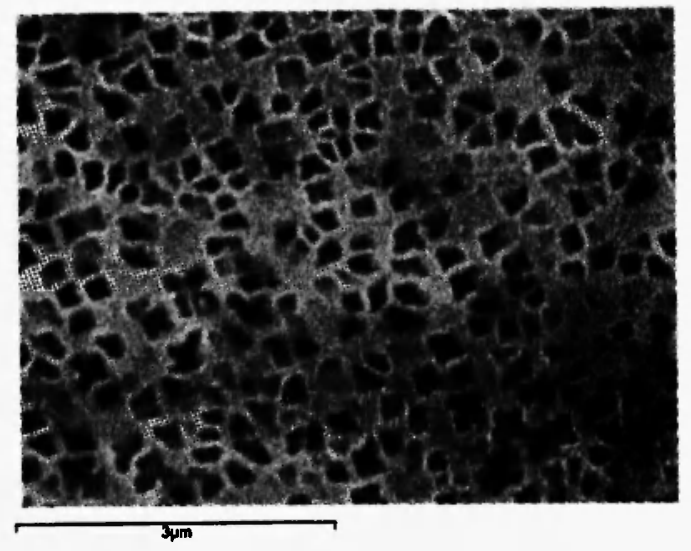

Fig. 3: After heat-treatment at $1118 \mathrm{~K}$ for $86.4 \mathrm{ks}$ (AC); Condition No. 1 


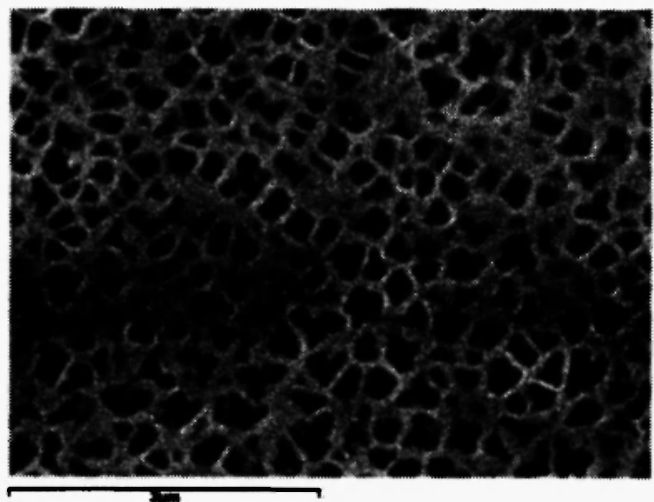

Fig. 4: After heat-treatment at $1198 \mathrm{~K}$ for $3.6 \mathrm{ks}$ (AC), and $1118 \mathrm{~K}$ for $86.4 \mathrm{ks}$ (AC); Condition No. 2

Figure 4 shows the HIPed microstructure followed with primary aging at $1198 \mathrm{~K}$ for $3.6 \mathrm{ks}$ and then secondary aging at $1118 \mathrm{~K}$ for $86.4 \mathrm{ks}$. It comprises of homogeneous distribution of precipitated gamma prime particles much more cubic shape and coarser size in matrix than those of heat-treated microstructure of program No.1. The size of these coarse precipitated particles is in the range of $0.2-0.39 \mu \mathrm{m}$. However, it should be noted that the volume fraction of precipitated phases is slightly higher than that of microstructure in program No.1. It should be pointed out that the inserted primary aging had small effect on the obtained microstructure characteristics. During primary aging at
$1198 \mathrm{~K}$, the gamma prime phase could slightly reprecipitate throughout the matrix and continue to grow under secondary aging period, resulting in slightly coarser size and higher volume fraction of $\gamma^{\prime}$ particles, see Figs. 5 and 6.

Figure 7 shows the HIPed microstructure followed with primary aging at $1328 \mathrm{~K}$ for $3.6 \mathrm{ks}$ and then secondary aging at $1118 \mathrm{~K}$ for $86.4 \mathrm{ks}$. The microstructure consists of fine gamma prime particles in mixing round-cubic shape precipitating uniformly throughout the matrix. The size of precipitated gamma prime particles is in the range of $0.2-0.4 \mu \mathrm{m}$ with a slightly higher volume fraction than those of conditions 1 and 2 . The secondary aging at $1328 \mathrm{~K}$ for $3.6 \mathrm{ks}$ could have an influence over the morphology of $\gamma^{\prime}$ particles, which is different from the lower temperature aging (at $1198 \mathrm{~K})$. During this very high temperature aging (1328 $\mathrm{K})$, gamma prime particles could precipitate into the matrix but in a slightly coarser size comparing to the microstructure after aging at lower temperature (1198 $\mathrm{K})$. However, the obtained volume fraction of gamma prime phase is higher than that of program No.2. After secondary aging at $1118 \mathrm{~K}$ for $86.4 \mathrm{ks}$, the size of gamma prime increased quite uniformly.

The solution treatment at $1398 \mathrm{~K}$ for $7.2 \mathrm{ks}$ had a great effect on microstructure characteristics. The solutioning at the temperature provided morphology with bimodal $\gamma^{\prime}$ phase precipitation, as shown in Figs.

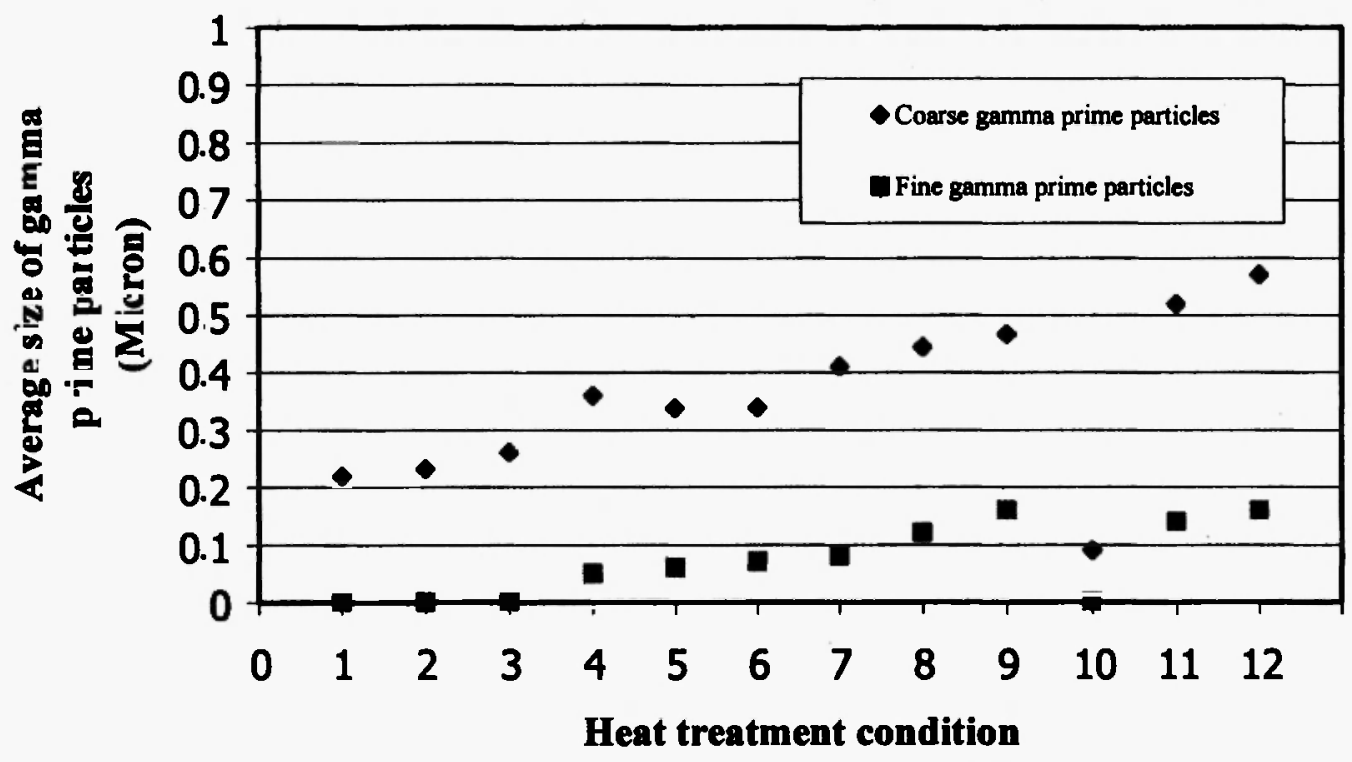

Fig. 5: The relationship between heat treatment condition and average size of $\gamma^{\prime}$ particles 


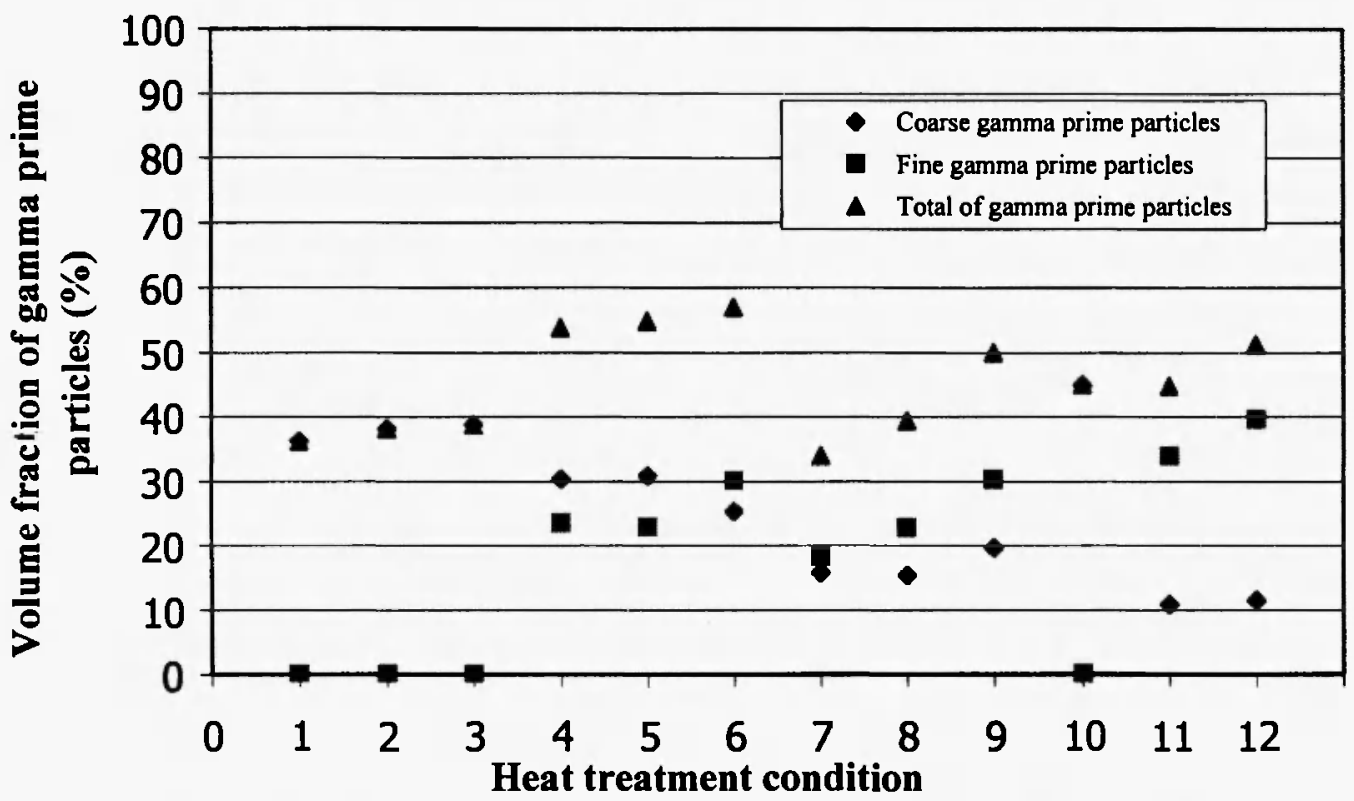

Fig. 6: The relationship between heat treatment condition and volume fraction of $\gamma^{\prime}$ particles

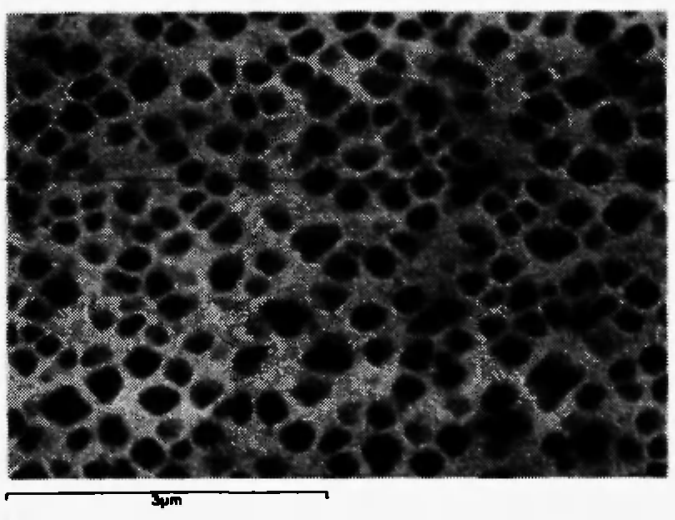

Fig. 7: After heat-treatment at $1328 \mathrm{~K}$ for $3.6 \mathrm{ks}$ (AC), and $1118 \mathrm{~K}$ for $86.4 \mathrm{ks}(\mathrm{AC})$; Condition No. 3

8-10. The average diameter size of $\gamma^{\prime}$ particles was about 0.35 and $0.05 \mu \mathrm{m}$ for coarse and very fine particles, respectively. Furthermore, this solutioning resulted in more cubic shape of coarse $\gamma$ ' particles. The solutioning at $1398 \mathrm{~K}$ for $7.2 \mathrm{ks}$ caused more dissolution into matrix of previous or residual coarse $\gamma^{\prime}$ particles. After final aging at $1118 \mathrm{~K}$ for $86.4 \mathrm{ks}$ with or without primary aging, coarse $\gamma$ ' particles could uniformly reprecipitate into the matrix with coarser size and higher volume fraction of total $\gamma$ ' precipitated phase comparing to those final microstructures according to conditions No. 1-3. The addition of primary aging (at both $1198 \mathrm{~K}$ and $1328 \mathrm{~K}$ for $3.6 \mathrm{ks}$ ) had a slight effect on early

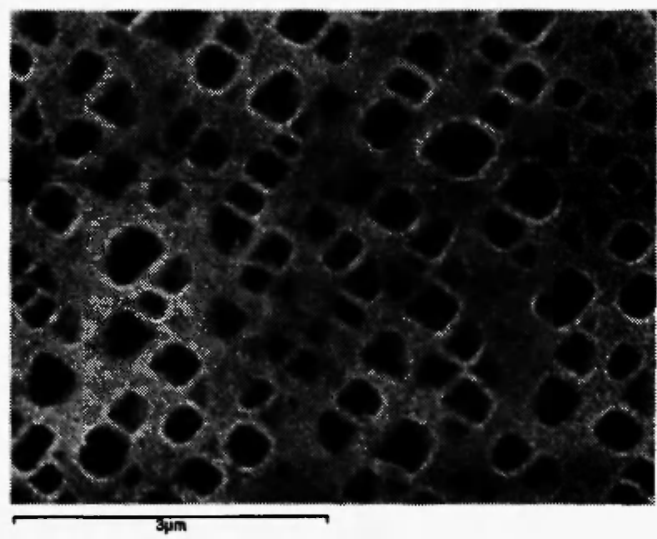

Fig. 8: After heat-treatment at $1398 \mathrm{~K}$ for $7.2 \mathrm{ks}(\mathrm{AC})$ and $1118 \mathrm{~K}$ for $86.4 \mathrm{ks}(\mathrm{AC})$; Condition No. 4

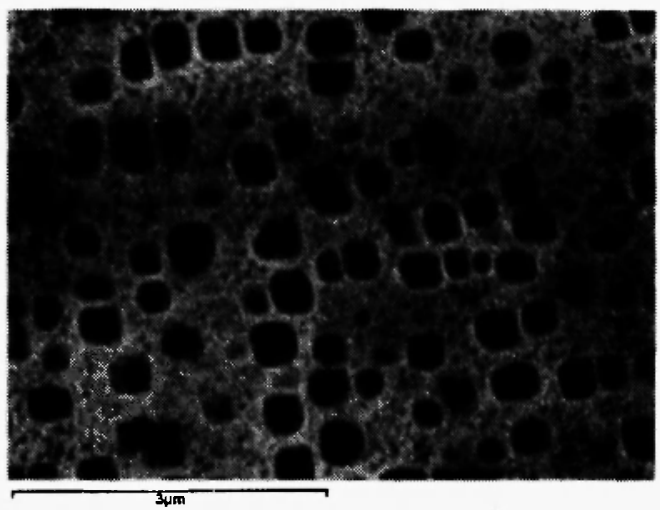

Fig. 9: After heat-treatment at $1398 \mathrm{~K}$ for $7.2 \mathrm{ks}$ (AC), $1198 \mathrm{~K}$ for $3.6 \mathrm{ks}(\mathrm{AC})$, and $1118 \mathrm{~K}$ for $86.4 \mathrm{ks}$ (AC); Condition No. 5 


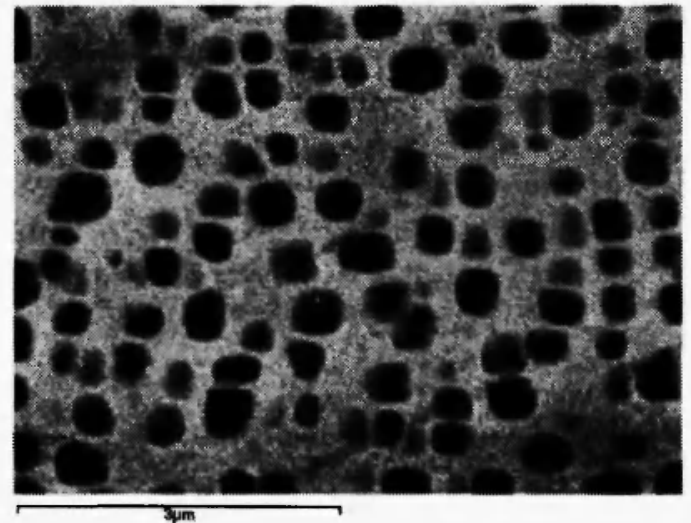

Fig. 10: After heat-treatment at $1398 \mathrm{~K}$ for $7.2 \mathrm{ks}$

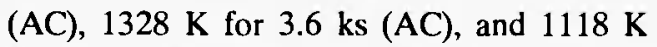
for $86.4 \mathrm{ks}$ (AC); Condition No. 6

precipitation and coarsening of very fine $\gamma^{\prime}$ particles. These earlier $\gamma^{\prime}$ precipitated particles could lead to the smaller size of coarse $\gamma^{\prime}$ particles during final aging.

Figures 11-13 show the effect of solution treatment at $1448 \mathrm{~K}$ for $7.2 \mathrm{ks}$ on final microstructures. Comparing to microstructures with the lower solutioning temperature (at $1398 \mathrm{~K}$ ) of conditions No. $1-3$, it was found that this higher temperature of solutioning provided the coarser average size of precipitated $\gamma^{\prime}$ particles, see Fig. 5. However, the volume fractions of coarse $\gamma^{\prime}$ particles in these final microstructures with $1448 \mathrm{~K}$-solutioning were less than those of final microstructures according to conditions No. 1-6. The dispersed coarse $\gamma^{\prime}$ particles in matrix should be the result of $\gamma^{\prime}$ precipitation during long term

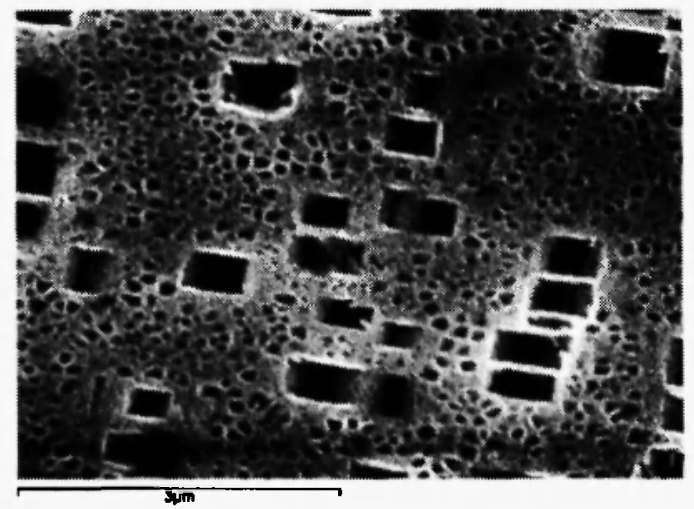

Fig. 11: After heat-treatment at $1448 \mathrm{~K}$ for $7.2 \mathrm{ks}$ (AC) and $1118 \mathrm{~K}$ for $86.4 \mathrm{ks}$ (AC); Condition No. 7

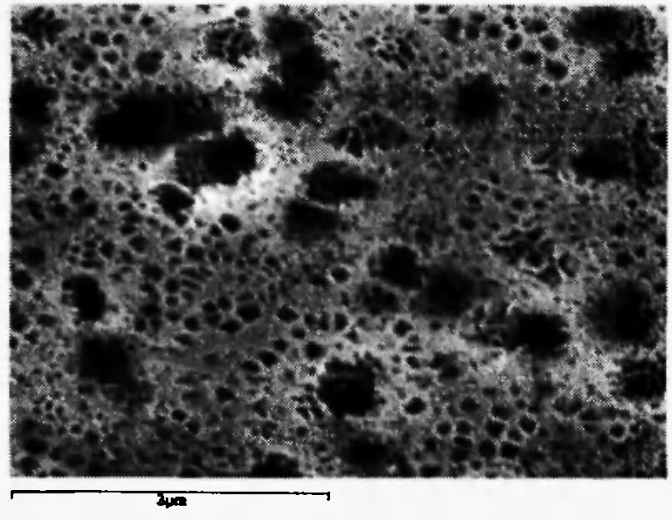

Fig. 12: After heat-treatment at $1448 \mathrm{~K}$ for $7.2 \mathrm{ks}$ (AC), $1198 \mathrm{~K}$ for $3.6 \mathrm{ks}$ (AC), and $1118 \mathrm{~K}$ for $86.4 \mathrm{ks}$ (AC); Condition No. 8

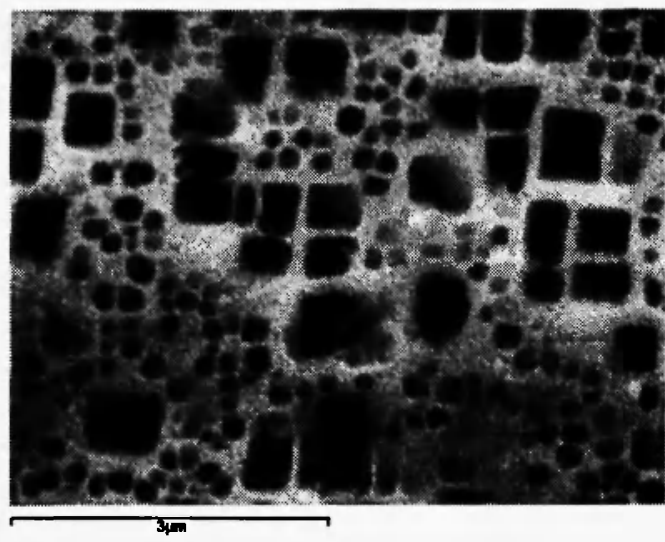

Fig. 13: After heat-treatment at $1448 \mathrm{~K}$ for $7.2 \mathrm{ks}$ (AC), $1328 \mathrm{~K}$ for $3.6 \mathrm{ks}(\mathrm{AC})$, and $1118 \mathrm{~K}$ for 86.4 ks (AC); Condition No. 9

aging after solutioning. The primary aging at $1198 \mathrm{~K}$ for $3.6 \mathrm{ks}$ dic not provide any significant effect on microstruct re but only resulted in shape of coarse $\gamma^{\prime}$ particles co nparing to microstructures without primary aging. Hc rever, when primary aging at higher temperatur of $1328 \mathrm{~K}$ for $3.6 \mathrm{ks}$ was applied, the $\gamma$ '

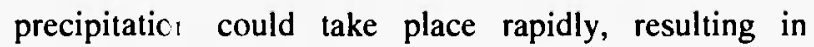
higher vol 1 , e fraction and coarser size of both coarse and fine $\gamma$ irticles after final aging.

The so: ": oning at the highest tested temperature of $1478 \mathrm{~K}$ for $2 \mathrm{ks}$ could cause very high dissolution of previous or 'sidual $\gamma$ ' particles after HIP process into the matrix. ' he obtained microstructures after this solutioning nere expected to be very highly homogeneo,: Therefore, during the next step, long 
term aging at $1118 \mathrm{~K}$ for $86.4 \mathrm{ks}$, the $\gamma^{\prime}$ particles could uniformly reprecipitate in single size and round shape. It should be noted that no coarse $\gamma$ ' particle was observed (see Fig. 14). However, when inserting primary aging process between solutioning and final aging (or secondary aging), this could lead to rapid precipitation of both coarse and very fine $\gamma^{\prime}$ particles during primary and secondary agings, Figs. 15 and 16. These heat treatment conditions provided the maximum particle sizes, especially of coarse $\gamma^{\prime}$ particles (see Fig. 5). However, it should be pointed out that the volume fractions of coarse $\gamma$ ' particles were the lowest ones comparing to those of other heat treatment conditions. The higher temperature $(1328 \mathrm{~K})$ of primary aging in condition No. 12 resulted in more slightly coarsening of

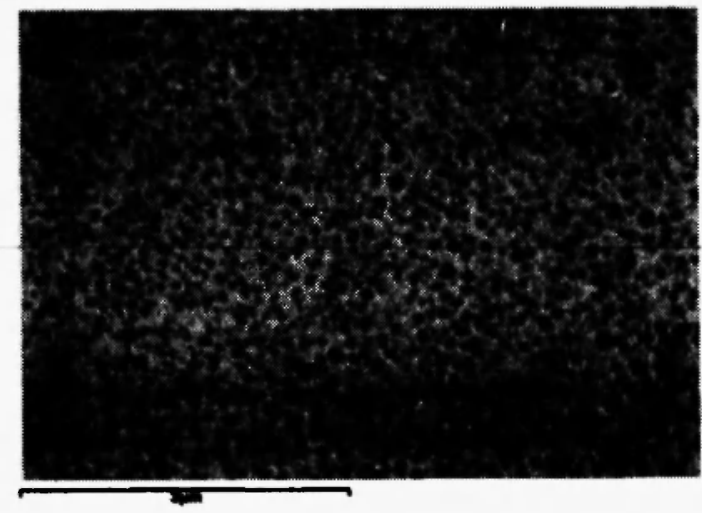

Fig. 14: After heat-treatment at $1478 \mathrm{~K}$ for $7.2 \mathrm{ks}$ (AC) and $1118 \mathrm{~K}$ for $86.4 \mathrm{ks}$ (AC); Condition No. 10

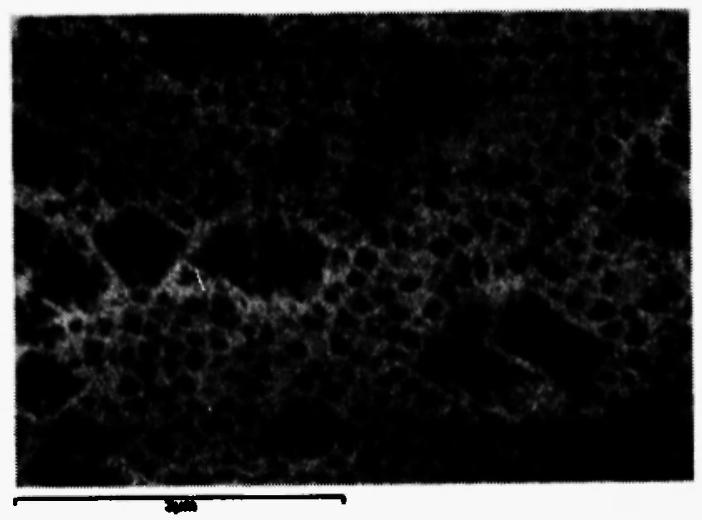

Fig. 15: After heat-treatment at $1478 \mathrm{~K}$ for $7.2 \mathrm{ks}$ (AC), $1198 \mathrm{~K}$ for $3.6 \mathrm{ks}(\mathrm{AC})$, and $1118 \mathrm{~K}$ for $86.4 \mathrm{ks}$ (AC); Condition No. 11

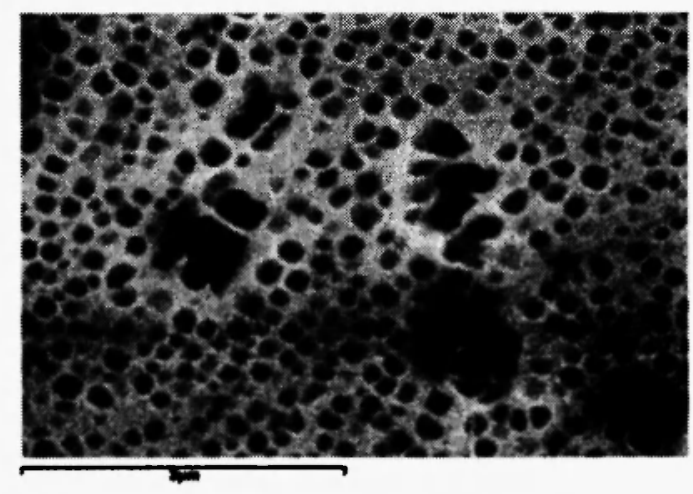

Fig. 16: After heat-treatment at $1478 \mathrm{~K}$ for $7.2 \mathrm{ks}$ (AC), $1328 \mathrm{~K}$ for $3.6 \mathrm{ks}$ (AC), and $1118 \mathrm{~K}$ for $86.4 \mathrm{ks}$ (AC); Condition No. 12

$\gamma$ ' particles than that of the lower primary aging temperature of $1198 \mathrm{~K}$ in condition No. 11.

\section{CONCLUSION}

1. The most proper solutioning temperature in this experimental program that should be done after HIP process is $1398 \mathrm{~K}$, which could provide the final microstructures with highest volume fractions with proper shape and size of coarse $\gamma$ ' particles.

2. The addition of primary aging could assist in more uniform distribution of both coarse and very fine $\gamma^{\prime}$ particles as well as the increase of volume fractions comparing to those without primary aging. However, applying the primary aging after very high solutioning temperatures (of $1448 \mathrm{~K}$ and $1478 \mathrm{~K}$ ) would lead to fast and abnormal precipitation, resulting in partial coarse $\gamma^{\prime}$ particles, conditions No. 7-12.

3. The most proper heat treatment conditions after HIP process for the alloy should be conditions No. 4 (standard heat treatment), 5, and 6 due to their highest volume fractions of $\gamma^{\prime}$ particles, which were nearly $60 \%$, as well as coarse $\gamma^{\prime}$ particles that precipitated uniformly and densely. However, mechanical testing, especially at elevated temperatures such as creep, fatigue and thermal fatigue should be performed in further works to evaluate and confirm the relationship between the rejuvenated microstructures and mechanical properties. 


\section{ACKNOWLEDGEMENTS}

This research work was financially supported by the postdoctoral research grant (No. MGR 4880088) from The Thailand Research Fund (TRF) and The Commission of Higher Education of Thailand. Special thanks are also extended to Mr. W. Hormkrajai at Electricity Generating Authority of Thailand (EGAT), Nonthaburi, Thailand for material support and technical help.

\section{REFERENCES}

1. J. A. Daleo, H. A. Ellison, and D.H. Boone, J. Eng. Gas Turb. Power, 124, 571-579 (2002).

2. P. Wangyao, T. Korath, T. Harnvirojkul, and W. Homkrajai, J. Met. Mater. Miner., 14 (1), 49-59 (2004).

3. T. Kvackaj, J. Zrnik, V. Vrchovinsky, and P. Wangyao, High Temp. Mater. Process, 21 (6),
351-359 (2002).

4. T. Kvackaj, J. Zrnik, V. Vrchovinsky, and P. Wangyao, High Temp. Mater. Process, 22 (1), 57 62 (2003).

5. P. Wangyao, S. Joypradit, P. Tuengsook, W. Hromkrajai, and S. Khunthon, J. Met. Mater. Miner., 14 (1), 89-94 (2004).

6. P. Wangyao, V. Krongtong, W. Hromkrajai, P. Tuengsook, and N. Panich, J. Met. Mater. Miner., 16 (1), 55-62 (2006).

7. S. A. Sajjadi, S. Nategh, and R. I. L. Guthrie, Mat. Sci. Eng. A-Struct., 325, 484-489 (2002).

8. S. Nategh and S. A. Sajjadi, Mat. Sci. Eng. AStruct., 339, 103-108 (2003).

9. www.liburdi.com

10. S. A. Sajjadi, S. M. Zebrajad, R. I. L. Guthrie, and M. Isac, J. Mater. Process. Technol., 175, 376-381 (2001).

11. E. Lvova and D. Norsworthy, J. Mater. Eng. Perform., 10 (3), 299-312 (2001). 
